\title{
Pallet standards in agri-food sector: a brief survey
}

\author{
Alessandro Trevisani, Eleonora laccheri, Angelo Fabbri, Adriano Guarnieri \\ Department of Agricultural and Food Sciences, University of Bologna, Italy
}

\begin{abstract}
In food industry wooden pallet and fruit and vegetables crates are the most used for handling and delivering. Regulatory aspects and test procedure are relatively young as regards to the packaging sector of wooden. Currently many standards are in development or implementation. In this context the objective of the following paper is a brief overview on technical standards governing the use of wooden packaging, with particular reference to the agricultural-food sector. In this review, as wooden packaging, are taken into account, wood or its derivatives used to support, packaging and transport goods, such as cages, wooden pallets, wooden frame, wooden kegs, rods or timber. Particularly European standards are briefly described in their technical content and historic development. Market data, emerging technology and environmental problems are even recalled.
\end{abstract}

\section{Introduction}

Pallet is a portable platform on which goods are stored or moved. Pallet literally moves the world (Buehlmann et al., 2009). The main material used in food industry for pallet is wood.

The wooden packaging sector in Italy is relatively young in terms of regulatory aspects and related test procedures. Many of the specific standards are currently still being defined or acceptance (Mainardi, 2009). This is true even if the material is clearly known and studied since long time, particularly in the building engineering area. As regards the use of structural wood are active working groups and studies, often in full accordance with the International Standard

Correspondence: Eleonora Iaccheri, Department of Agricultural of Food Sciences (DISTAL), University of Bologna, P.zza Goidanich 60, 47522 Cesena (FC), Italy.

Fax: +39.0547 .382348 .

E-mail: eleonora.iaccheri4@unibo.it

Key words: food industry, pallet, standard.

Received for publication: 13 November 2013.

Accepted for publication: 8 April 2014.

(C) Copyright A. Trevisani et al., 2014

Licensee PAGEPress, Italy

Journal of Agricultural Engineering 2014; XLV:220

doi:10.4081/jae.2014.220

This article is distributed under the terms of the Creative Commons Attribution Noncommercial License (by-nc 3.0) which permits any noncommercial use, distribution, and reproduction in any medium, provided the original author(s) and source are credited.
Organisation (ISO), particularly devoted to the use in building constructions. Recently other areas such as packaging for transport and handling were involved. The legislation is most highly developed in European countries such as Sweden, France, Spain and especially Germany, as particularly highlighted by the development of the Deuthsches Institute für Normung (DIN) standards. European Union is actually engaged in translation of some specific German documents that are continuously developing in the context of building constructions.

In this context the objective of the following paper is a brief overview on technical standards governing the use of wooden packaging, with particular reference to the agricultural-food sector.

In this review, as wooden packaging, are even briefly taken into account, wood or its derivatives used to support, packaging and transport goods, such as cages, wooden pallets, wooden frame, wooden kegs, rods or timber.

\section{Market data and development of the food packaging}

The global packaging sector amount about 563,847 billion dollars, in 2009, of packaging container sales (World Packaging Organisation, 2008). Packaging pallet became a very important item which grows with global economy; it is used in a wide range of food and drink industry. Figure 1 shows that the largest packaging market in 2009 was the USA (127 million dollars), followed by Japan (59 million dollars) and China (50 million dollars); Italy ranked seventh (21 million dollars).

The rates of development of packaging sector, are not very high (about 2.6\% for the year 2012) mainly due to the downsizing of the area of cages for fruit and vegetables, as well as trends practically zero in the manufacturing industry. The packaging sector in Italy involves a business of about 29.3 billion euros (2012), equal to $6 \%$ of world production. Italy is the sixth world packaging producer, with a volume of $14,469,000$ tons, as reported in Table 1 .

The packaging sector confirms that it is food (38.1\%) the bigger area involved, followed by beverages (34\%) and non-food (28.5\%). Italian internal trades represent about $86 \%$ of the total, while about $42 \%$ of exports regards plastic packaging, followed by cellulosic and glass packaging as shown in Table 2. Imports represent only 7\% of consumption (Italian Institute of Packaging, 2013).

Metal packaging sector involves $60 \%$ food and beverages industries with 656 tons, in particularly cans for beverages and tomato that account respectively 50\% and $22 \%$. 2012 draw $3.4 \%$ increase of steel packaging due to trays and aluminium or stain wrapping sheet. Cellulosic packaging (4772 tons) concern over the $80 \%$ beverages bin where an evolution trend was observed thanks to the multi-covered packages used for example for milk (Mahalik et al., 2010). In the last few years plastic packages had a positive trend despite devolution in other sector, this is due to the increasing of the pre-packaging of fresh food and trifle packages. Otherwise in 2012 a little decrease was observed in relation to the unused of shopper and slighter packaging. 
In the years 2000-2009, demand for wood packaging has grown around 3\% (World Packaging Organisation, 2008). In Figure 2 are shown the values in US million \$ of wood packaging market in 2009. The most important countries are Europe with 15,434 (\$ million), Asia with 11,033 (\$ million) and North America with 6120 (\$ million).

\section{Development of the International Standards for Phyto-sanitary Measures no. 15}

Wooden packaging is divided into three areas: pallet, fruit and vegetables crates and industrial wooden packaging (Alvarez and Trystan, 2000). In food industry pallet and fruit and vegetables crates are the most used. The develop rate are restrained due to the scaling of the fruit and vegetables sector. Packaging and box pallets are intended for repeated use while maintaining their service ability and their safe handling. They may be used for mechanical handling, bulk storage and transport. Box pallet shall be designed in order to allow stacking and some specific tests are conducted to verify this. Regulatory aspects and test procedure are relatively young as regards to the packaging sector of wooden. Currently many standards are in development or implementation.

The pallet related standards are still in continuous transformation, also due to the effect of the nascent needing related to the use of pallet with standardized sizes as stated by the European Pallet Association (EPAL) and to biological contamination problems as specified by the International Standards for Phyto-sanitary Measures no. 15 (ISPM 15). As an example, in recent periods, the supervisory authorities Chinese have changed the quarantine requirements for wooden packaging for imported goods. Particularly in 2011 over than 1.9 million of animal and vegetable goods exported from china were checked showing about 4000

Table 1. Wooden packages market in Italy (Italian Institute of Packaging, 2013).

\begin{tabular}{lcc} 
& 2011 & 2012 \\
Sales renue (million, euro) & 28,579 & 28,784 \\
Production (t/000) & 15,247 & 14,469 \\
\hline Export (t/000) & 2667 & 2531 \\
Import (t/000) & 1413 & 1411 \\
\hline Insiders (t/000) & 105,000 & 105,000 \\
Production-export+import (t/000) & 13,993 & 13,348 \\
\hline
\end{tabular}

Table 2. Production of the main packaging materials ( $t / 000)$ (Italian Institute of Packaging, 2013).

\begin{tabular}{lcc} 
& 2011 & 2012 \\
Steel & 693 & 656 \\
Aluminium & 99.3 & 103.3 \\
\hline Paper & 4938 & 4722 \\
Plastics & 2936 & 2779 \\
\hline Glass & 3590 & 3414 \\
Wood & 2401 & 2214 \\
\hline Others & 28 & 28 \\
Total & $14,685.3$ & $13,916.3$ \\
\hline
\end{tabular}

contaminated samples.

The EPAL is an organisation founded in 1995 as a result of the decay of the average quality of the park pallet in Europe, mainly due to the absence of procedures control by producers (e.g. quality of the wood, size, nails) and by the dealers/users frequently importing not standard pallet. The ISPM certification, that is a UN emanation, must instead be applied to all wood materials used for shipments to China. These provisions reflect the legislation related to wood packaging shipped in the United States. These latter have a phyto-sanitary regulations called 7 CFR 319.40, containing the conditions to reduce the risk of spreading harmful organisms related to the import of timber, updated to adopt the international standard ISPM-15. In the so-called phase I, from September 2005 to January 31, 2006 (a period of conformity informed) have not been stopped shipments with non-compliance wood packaging material (WPM). During this phase all of the unconformity coming from visual inspections by custom officers drives only to a special notation to the importer about the specific non-conformity. From July 2006 started a full implementation of the ban on the WPM as regulated by

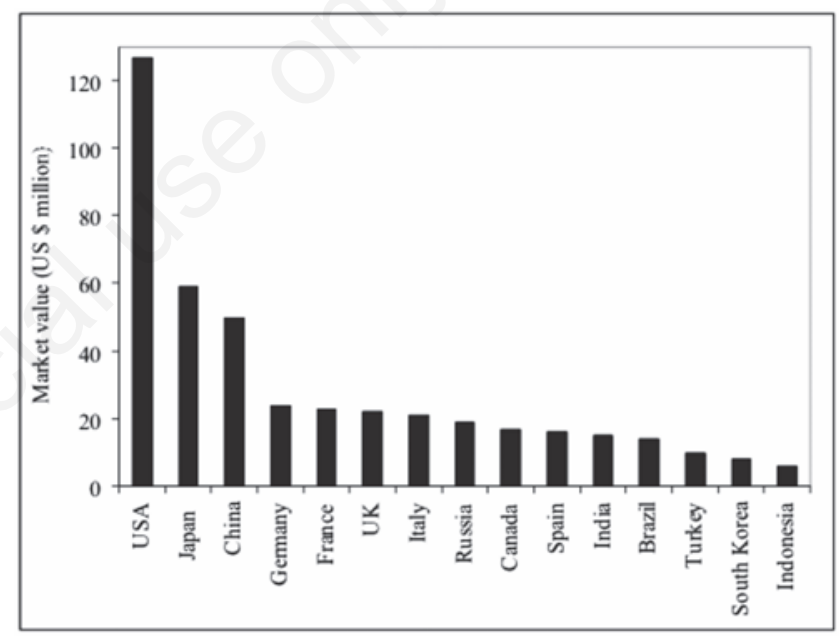

Figure 1. Global packaging market value; 2009 (data available from: http://worldpackaging.org).

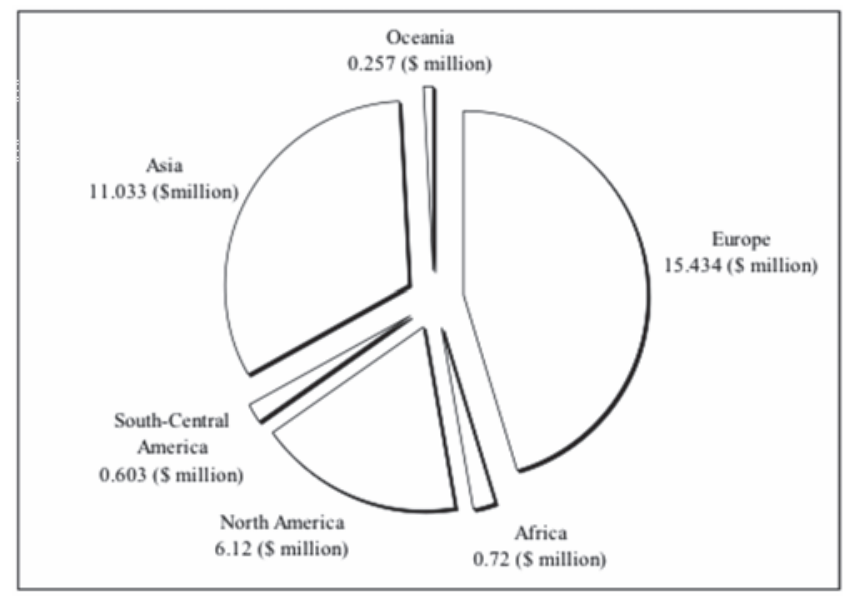

Figure 2. Wood packaging market value; 2009 (data available from: http://worldpackaging.org). 
point 319 , Cf. 7, and customers' authorities started to full enforce the prohibition of input for non-compliant pallets and crates.

The current European standards state that all types of WP must be subjected to heat treatment or fumigation before being shipped. It is also necessary that WP are marked with a special marking in order to certify the type of treatment carried out (Figure 3). The European disposition for WP establishes thermal treatment $\left(56^{\circ} \mathrm{C}\right.$ for $\left.30 \mathrm{~min}\right)$ or fumigation with methyl bromide.

Non-conformal WP are usually destroyed or may be returned to sender.

In standard development great attention was paid to aspects joined to dimensions, mechanical performance (sealing joints and wood) as well as environmental risks.

\section{European and Italian standards}

A summary description of standards for packaging sector, with specific references to wood and derivatives, applied to the agri-food sector follows. For every standard considered, a small description about the field of application is reported. The standards can concern both product or test. Product standards define the characteristics of conformity to which the product must comply with the possibility of classify the packaging on the basis of some technical parameters. Test standards describe the laboratory methods for packaging characterization.

\section{Product standard}

\section{ISO 445:2013(E) Pallets for materials handling - Vocabulary}

The ISO 445 defines terms relating to pallets for unit load methods of materials handling. It also includes informative added listing terms relating to unit load handling and slip sheets.

As regard the national standard UNI 9151 are widespread:

- UNI 9151-1:1998 Wooden packaging for more than $300 \mathrm{~kg}$ - Terms and definitions.

- UNI 9151-2:1998 Wooden packaging for more than $300 \mathrm{~kg}$ Requirements analysis.

- UNI 9151-3:1998 Wooden packaging for more than 300 kg - Sizing and embodiment.

The UNI 9151 is a product standard divided into three parts describing the necessary characteristics for the packaging able to transport loadings over $300 \mathrm{~kg}$. The first part is intended to define the terms used in subsequent parts so as to facilitate a uniform understanding in every nation of the requirements, with particular reference to the name of the individual components of the packaging. The same standard is also responsible for defining the intervals dimensional and eligible construction techniques.

The standard UNI 10858 is divided into 4 parts and regards packages not considered by UNI 9151:

- UNI 10858-1:2000 - Special wooden packaging for content up to $10^{4} \mathrm{~kg}$ and maximum dimensions 600x250x250 cm-Terms, definitions and requirements.

- UNI 10858-2:2000 - Special wooden packaging for content ranging from $300 \mathrm{~kg}$ to $10^{4} \mathrm{~kg}$ and maximum dimensions $600 \times 250 \times 250 \mathrm{~cm}$ Types and construction elements, classification and implementation.

- UNI 10858-3:2000 - Special wooden packaging for content less than

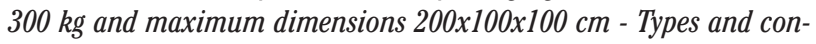
struction elements, classification and embodiment.

The standard reports in the title the word special, meaning that in general all the uses for which there is no different specification, such as modular speakers or cages for shipping sea/air (Figure 4).
The same standards in parts 2 and 3 provides respectively types, constructive elements, classification and construction of special packaging of wood for content of between 300 and $10,000 \mathrm{~kg}$, size range of maximum dimensions $600 \times 250 \times 250 \mathrm{~cm}$ and for content less than $300 \mathrm{~kg}$ and maximum dimensions $200 \times 100 \times 100 \mathrm{~cm}$. The standard does not have particular contents as test systems and/or constructive, being a simple review of size classes.

\section{UNI EN 13382:2004 Pallet dishes for the movement of goods - Principal dimensions}

UNI EN 13382 deals with dimensional analysis and the tolerances of packaging and pallet. This European Standard specifies the principal dimensions and tolerances for new single-deck and double-deck nonreversible flat pallets of all entry types related to their transportation and handling by pallet trucks, fork lift trucks and other appropriate equipment.

\section{ISO 6780:2003(E) Flats pallets for intercontinental materials handling - Principal dimensions and tolerances}

The International standard 6780 specifies the principal dimensions and tolerances for new single deck and double deck, reversible and non-reversible flat pallet, of all entry types and made of any material, related to their transportation and handling by fork lift trucks and other appropriate equipment. Openings, clearances, chamfers and wings are also included for an efficient handling.

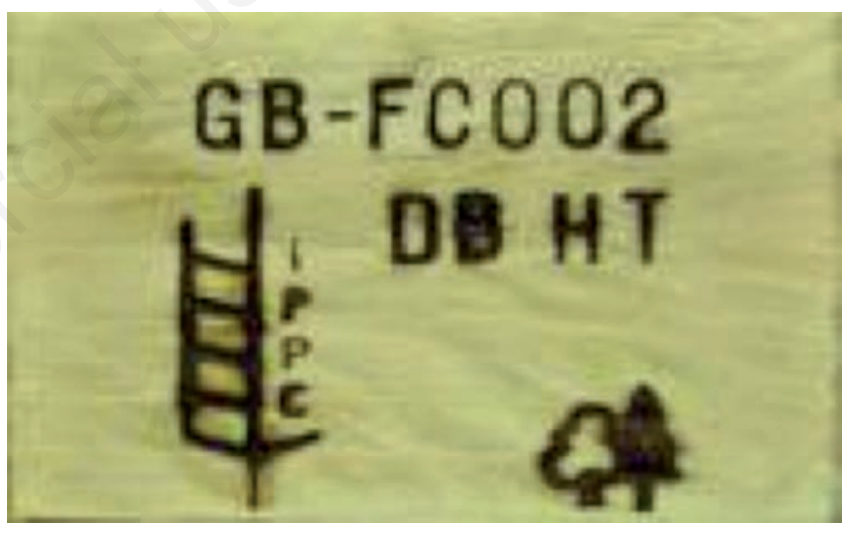

Figure 3. Example of marking International Standards for Phytosanitary Measures no. 15 on wood packaging.

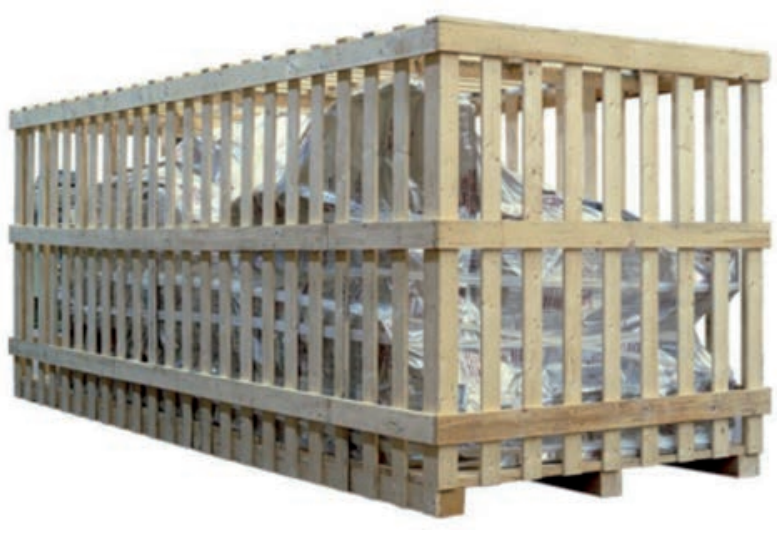

Figure 4. Special wood packaging for transport by sea. 
ISO 18333: 2002 Pallets for materials handling - Quality of new wooden components for flat pallets

Efficient international transportation of products depends on both pallet strength and functionality, or fit to the material handling system. The purpose of ISO 18333 is to establish internationally recognized minimum acceptable quality levels for wooden parts commonly used for assembly of timber pallets. Particularly these parts that can affect pallet performance are stringers, stringer-boards, blocks and deck-boards.

UNI EN 12246:2000 Quality classification of wood used in pallets and packaging

The standard 12246 defines the quality classes of wood eligible to be used for wood packaging and pallet.

UNI EN 12248:2000 Sawn wood used in industrial packaging Size and preferential eligible waste

UNI EN 12249:2000 Sawn wood used in pallet - Eligible waste and guide to the size

Particularly, UNI 12249-12248 specifies two classes of sizes, thickness, width and length tolerances of wood elements used in pallet assembly. These standards consider permitted deviations (due to variability in sawing and processing) from target thicknesses and widths for sawn timber used in industrial packaging and pallet when measured at a defined reference moisture content. It also gives preferential sizes of this timber and pallet.

UNI 11419: 2011 Minimum requirements for the establishment of a technical specification for the supply

The standard 11419 specifies the minimum requirements that must be contained in a technical specification for supplying a new manufactured pallet, independently by the specific material, at the time of delivery to the customer.

This standard must be applied to each individual contract between supplier and the customer. The specifications may be constituted by two technical sections, one including the data common to all pallet of the same kind and another, more specific, with deep technical details.

Pallets are subjected to maintenance, in particular those intended for reuse, and obviously also pallet repaired must agree with standards.

\section{UNI EN ISO 18613:2003 Pallet wooden plates reparation}

Particularly UNI EN ISO 18613 considers pallet reparation. The provision specifies the maximum number of defects and damage allowed before a wooden plane pallet should be repaired, and defines the minimum criteria of repair that must be applied. The pallets marked as unacceptable must be repaired according to EN ISO 18613. It is allowed maximum three repairs in three distinct phases. Pallets which cannot make amends for reuse in line must be rejected. Technologies exist to allow reusing and recycling discarded pallets and creating opportunities to produce value added wood products.

UNI EN 13698-1:2004 Product specifies for pallet - Part 1: Specification of manufacture for wooden pallet plates $800 \times 1200 \mathrm{~mm}$

UNI EN 13698-2:2009 Product specifies for pallet - Part 2: Specification of manufacture for wooden pallet plates $1000 \mathrm{~mm}$ x $1200 \mathrm{~mm}$

UNI 13698 is divided into two parts (width 800 and $1000 \mathrm{~mm}$ ), specifies the characteristics of the reusable pallet plates, two-planes, nonreversible, at 4 way and 9 blocks, suitable for transport, storage, handling or exchange (Figure 5). It also gives some requirements for manufacture and marking and addresses the issue of safety.

\section{ISO 12776:2008 (E) Pallet - Slip sheet}

This standard has introduced, since a couple of years ago, an alternative in using pallet: a slip-sheet, as shows in Figure 6, can be used as a base on which items are assembled as a unit load for handling and transporting. To use a slip-sheet, made of a thin sheet material, a conventional lift truck is equipped with a special attachment for gripping, pulling and pushing the slip-sheeted unit loads. If all lift trucks in the distribution chain are equipped with the proper attachment (permanent or removable) a slip sheet can be the only material-handling base required. However, the slip-sheet may also be used in conjunction with a pallet. A slip-sheet provides an inexpensive and lightweight unit-load base that occupies little shipping space and is more easily disposed than conventional pallets.

\section{Test standards}

UNI EN ISO 8611-1:2012 Pallets for the handling of goods - Pallets dishes - Part 1: test methods

The standard 8611-1 specifies the test methods available for evaluating new flat pallets for materials handling. The test methods are split into groups for nominal load testing, maximum working load testing and durability comparison testing. It is not intended to be applied to pallets with a fixed superstructure or a rigid self-supporting container that can be mechanically attached to the pallet, contributing to the strength of the pallet.

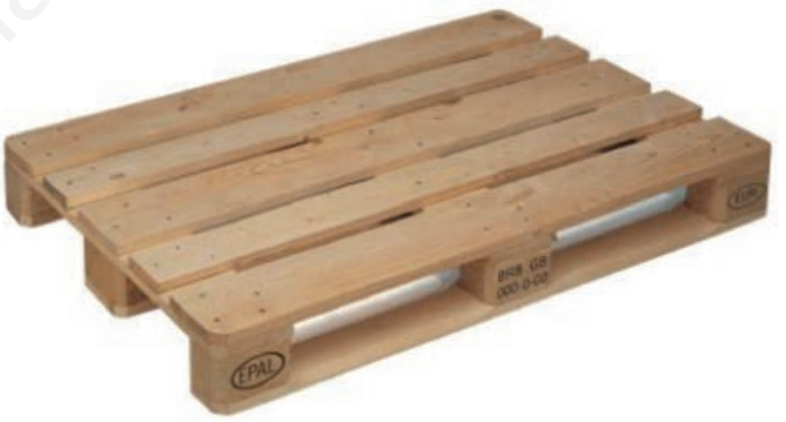

Figure 5. Pallet with 9 blocks.

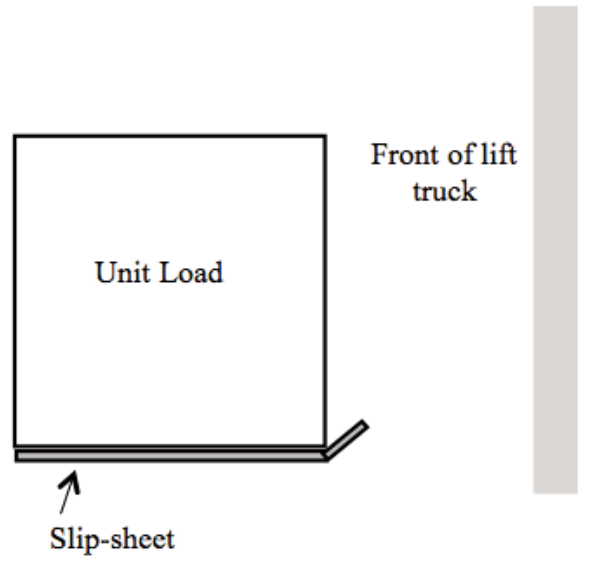

Figure 6. Example of slip sheet used rather than pallet. 
UNI EN ISO 8611-2:2012 Pallets for materials handling - Flat pallets - Part 2: Performance requirements and selection of tests

The standard 8611-2 point out the performance requirements to establish nominal loads for new flat pallets. It also defines the tests required for new flat pallets in various handling environments and the performance requirements for tests with payloads. It is not intended to apply to pallets with a fixed superstructure or a rigid, self-supporting container that can be mechanically attached to the pallet contributing to its strength.

UNI EN ISO 8611-3:2012 Pallets for materials handling - Flat pallets - Part 3: Maximum working loads

The standard 8611-3 describes the determination of maximum working load for new flat pallets with known payloads in different handling environments. The application field reflects that of part 1 and 2 .

UNI EN ISO 8611-4:2012 Pallets for materials handling - Flat pallets - Part 4: Procedure for predicting creep responses in stiffness tests for plastic pallets using regression analyses

The standard 8611-4 presents a procedure for estimation of creep responses in stiffness tests for plastic pallets. Deflections during full load and relaxation periods are predicted by a procedure based on regression analyses.

UNI EN ISO 12777-1:2009 Test methods for pallet assembly. Determination of flexural strength of nails of the pallets, other connecting elements without the head and nails to $U$

UNI EN ISO 12777-2:2001 Test methods for pallet junctions Determination of resistance to the extraction of tip and head of the nails and the clips for pallet

UNI EN ISO 12777-3:2004 Test methods for pallet junctions Determination of resistance of pallet junctions

UNI EN ISO 12777 is a test standard. The standardized properties are related to the flexural strength of the joining elements and to the extraction resistance of nails and staples. Particular attention is paid to the type of wood used as this can affect the result.

It describes test methods for the determination of the bending resistance of pallet nails, staples and other dowel-type fasteners. It includes test for the ultimate strength in static bending and impact bend resistance. These test methods apply to all types of nails.

Particularly, 12777-3 specifies methods to determining the resistance of pallet joints primarily to static load by determining the strength and stiffness of nailed or stapled joints, wood to wood, wood to woodbased materials, wood to plastics or plastics to plastics. This part is applicable to joints with all types of nails up to $7 \mathrm{~mm}$ diameter (including plain shank, helical, annular ring, barbed and twisted) and with staples.

UNI 11066:2003 Custom reusable wooden pallet - Requirements of design, construction, performance and test methods

This standard is designed to be applicable to custom reusable pallets and consider both aspects of the product (sizing, geometry, fasteners) and test methods.

\section{UNI EN 13626:2003 Packaging - Pallet containers - General requirements and test methods}

This European Standard draft sets out the requirements regarding the use of reusable box pallets as well as the tests to be passed by any such box pallets intended for the storage handling and transport of various product. 13626:2003 shows requirements and gives recommenda- tions for suitable steel structures for drilling and well-servicing operations in the petroleum industry, provides a uniform method of rating the structures, and provides two product specification levels.

UNI 10920:2001 Guide for the application of the standards for the implementation and the use of wooden packaging and special

UNI 10986:2002 Wooden packaging and special - audits - principles, criteria and methods of managing

UNI standards 10920 and 10986 provide information on the proper management of audits carried out inside wooden packaging manufacturers companies.

\section{UNI 13194:2011 (E) Box pallets - Principal requirements and test} methods

The European standard 13194 provides definitions and specifies principal requirements and test methods for box pallets, excluding tank and silo pallets as defined in ISO 445. It is performance-based, no minimum values are fixed. The performances are evaluated in relation to the load capacity of a box pallet carrying a uniformly distributed load used as test load. However, it is recognized that the maximum working load could be smaller or larger than the nominal load of a box pallet. Therefore, the allowable maximum load for a given design of box pallet varies according to the characteristics of the type of load carried. So this international standard is addressed to the performance of the box pallet only and not to its content.

\section{UNI EN 975-2009 Sawn timber - Appearance grading of hard- woods}

This European Standard goes into detail of the rules determining the quality of appearance graded sawn timber. It describes various grades of temperate hardwood rough sawn timber and regularized timber for which it lays down denominations and definitions. It also provides rules for composition and acceptance of batches. This standard dispenses minimum requirements for each grade classification. Sawn timber not included within limits given in this standard may be defined, if necessary, by contract specifications established on the basis of this standard. This standard applies to grading of green and dried timber. Characteristics apply at the time of grading. This standard does not apply to the strength grading of structural timber or to sawn timber for pallets.

\section{Pallets towards new technologies}

Wood pallets are the most used over years (Clarke, 2004) but material preferences is slowly varying in dependence of requirements in terms of performance and costs. The reasons of wood dominance were low material and production costs combined with the relative abundance of wood and its sustainable, versatile and environmentally friendly applications. The increasing demand for woody biomass for consumption and bio-energy generation could create incentives to avoid land filling wood pallets. Furthermore the increasing of the cost of the pallet raw material offer higher returns for reusing or recycling discarded pallets.

Remanufactured pallets, wood flooring, wood cement panels and bricks, mulch, boiler fuel and alcohols like ethanol are the recycling form of wooden pallet.

Different materials have been developed to replace solid wood and are defined as composites. The term composite describe any wood material made of smaller pieces and glued together (Maloney, 1996). Composites include moulded products, lumber, large timbers and products made with combinations of wood and other materials. Composites utilize what previously was wasted, such as wood residue, or few used 
or non-commercial species. There are different composite materials that can be grouped, for example into engineered wood products (EWP) or medium density fibreboard (MDF) (Maloney, 1996). EWP are plywood, variations of structural panels and glued laminated timber. MDF are substitute for clear lumber, it does not have a grain structure but finished and overlay can be used to provide product that looks and have functionality like wood.

Wood and wooden composites pallets could be cheap compared to non-wood pallets but they have a lot of disadvantage: degradation due to environmental factor, unreliable performance of the pallet over a period of time due to the method of fastening members of the pallet by nailing or screwing.

Due to these disadvantages, some pallet manufacturers use metals, paper and plastics for pallet manufacturing. Other materials are used also for regulatory reasons. For example, the grocery industry uses plastic pallets to be conforming to sanitary regulations, while metal pallets are used in closed loop material systems for their durability.

Plastic pallets are lightweight, fairly strong and durable and now are increasingly used in the handling industry, replacing conventional wood pallets. Plastic pallets are, however, three to five times more expensive than wood pallets (Soury et al., 2009), though the extra cost is usually offset by the number of trips and shipments that can be achieved with plastic pallets compared to the wooden pallets. The main disadvantage of plastic pallets is its non-biodegradable property, which is environmentally hazardous if disposed or burnt. Recycling plastic pallets is a remedy although expensive (Soury et al., 2009).

Wood-plastic composite (WPC) is a new material and its use is rapidly growing. WPC is made by mixture of wood (in shape of sawdust) and polymeric materials (such as polyethylene and polypropylene). As for wooden pallet, WPC pallet are often assembled by fastening medium such as nails, rivets and screws.

In manufacturing pallets, made of WPC, the profiles of the pallet are produced via the extrusion process. An advantage of using extrusion process is the capability of designing and optimizing the profile, and this can be enhanced by computer-aided design of the extrusion die. It must be mentioned that manufacturing WPC pallet in one piece using injection-moulding process is highly challenging due to the high possibility of wood burning. This is because this process accompanies a high shear rate due to the rapid injection speed, thus generating excessive heat. The existing wood-plastic pallets are mainly heavy weighted so they are not favourable to industries. Thus, it is essential to reduce the mass to an acceptable level. This mass reduction must be performed without compromising the pallet load endurance. Hence, it is required an optimization of pallet profiles.

Actually only one technical document on WPC is available, the CEN/TS 15534-2:2008-plastic-wood composites (WPC), part 2: material characterization.

Paper pallets represent a limited market and include corrugated, honeycomb, solid fibreboard and moulded pulp. Paper pallets find acceptance mainly within niche markets such as new markets opened driven by international pest regulations and increased airfreight shipping with weight based charges (Mahalik and Nambiar, 2010). General advantages of paper pallets concern the light weighting, easy recycle, smooth deck dry surface and bug free. Disadvantages are higher than wood, susceptible to moisture, lack of stiffness with flexible loads, low durability, and low product protection.

Metal pallets are produced with different materials include carbon steel, stainless steel, and aluminium. Of these, carbon steel offers excellent durability at the lowest cost. Stainless doesn't need a paint coating, and is preferred for such applications as clean room environments. Aluminium offers the durability of metal at a lighter weight. Compared to wood carbon steel, stainless and aluminium units are more expensive.

Considering a long term cost, carbon steel, stainless and aluminium can be competitive with wood and evaluated as cheaper. General advantages are strength, stiffness, durability, bug free, no splinters, sanitary, and recyclable. Disadvantages are higher initial price, weight, low friction, and susceptible to rusting (carbon steel). Metal is primarily used in captive or closed loop environments where durability and product protection are key measures. Metal units today are increasingly price competitive and lighter in weight. Primary industries include automotive, pharmaceutical, lawn tractors, motorcycles, and tires.

\section{References}

Alvarez G., Trystan G. 2000. Design of a new strategy for the control of the refrigeration process: fruit and vegetables conditioned in a pallet. Food Control 6:347-55.

Buehlmann U., Bumgardner M., Fluharty T. 2009. Ban on land filling of wooden pallets in North Carolina: an assessment of recycling and industry capacity. J. Clean. Prod. 17:271-5.

Clarke J. 2004. Pallets 101: Industry overview and wood, plastic, paper and metal options. PreShipment Testing, pp 20-3. Available from: http://www.ista.org/forms/PST2004Issue4.pdf

Italian Institute of Packaging. 2013. [Italian packaging industry]. Istituto Italiano Imballaggio, Milano, Italy. Available from: http://www.istitutoimballaggio.it/wp-content/uploads/2011/10/ Generale-20131.pdf [In Italian].

Mahalik N.P., Nambiar A.N. 2010. Trends in food packaging and manufacturing system and technology. J. Food Sci. Technol. 21:117-28.

Mainardi G. 2009. Industrial wood packaging guidelines. ConLegno, Milano, Italy.

Maloney T.M. 1996. The family of wood composite materials. Forest Prod. J. 46:19-26.

Soury E., Behravesh A.H., Rouhani Esfahani E., Zolfaghari A. 2009. Design, optimization and manufacturing of wood-plastic composite pallet. Materials Design 30:4183-91.

World Packaging Organisation (WP0). 2008. Market statistic and future trends in global packaging. World Packaging Organisation (WP0), Brazil, pp 1-45. Available from: http://www.worldpackaging.org/ 